\title{
Analysis on the Current Situation and Countermeasure of Football in Colleges
}

\author{
Shuaicheng Luo and Quan Xu \\ NanChang Institute of Science \& Technology, Nanchang,330108
}

\begin{abstract}
Keywords: Campus football; Humanistic advantage; Chinese football
\end{abstract}
\begin{abstract}
Colleges is one of the training bases for football talents. The development of football in colleges plays a guiding role in the development of Chinese football. To a certain extent, the good and bad effectiveness of the college football development indirectly reflects the overall situation of China's campus football. As we all know, college is a wide range of talent pool with rich cultural atmosphere, rich resources, communication platform, so how to use these talents to achieve resource integration and optimization, to build a comprehensive college football development system and promote the development of college football and the atmosphere of football and enhance the physical quality and will quality of college students, has become the focus of this study. This paper studied the present situation of college football, the talent advantages of college football, and how to use these talents to provide constructive countermeasures for campus football. Besides, we puts forward the idea of integrating university resources, perfecting amateur training system and the construction of college football network system measures and ideas, making this article has a strong theoretical significance, but also has a high practical value.
\end{abstract}

\section{Introduction}

With the college football as a course introduced into the classroom, more and more college students love football, with years of construction and development, college campus football has not only simply carry the function of entertaining everyone's physical and mental, from a certain meaning: Today's college football not only bear the position of directing the development of China's campus football, and even will be arsenal to output China's reserve football talent in the future. However, the development of college football in colleges exist the problem while there is a huge advantage, if we want our college football to get huge development by leaps and bounds, we must take useful exploration on its existence and potential advantages. To strengthen the ideological and political work of college football in colleges of China: to attach great importance to the culture education of football talents in colleges, to establish a "use football to nurture people" training ideas; football management, education department, social enterprises and families to work together; building coach team to achieve scientific guidance and training; to make full use of the humanities advantages of colleges. Only set off a football boom in the national colleges and universities, China's campus football can really use the humanities to achieve sustainable development.

\section{Analysis on Current Situation of Competition and Training System}

The college football training system is a complex training system, which is composed of many small links. Among them, in the college football training system, the players system and coaches system are undoubtedly the most important two links.

College Football Team is Different from the Professional Team. Due to the different disciplines and professional, it makes that different from other levels of campus football. Therefore, the composition of the college football team is generally made up of different courses and different professional classes, and even different campus students, to take centralized training at a fixed time. Because of the above series of reasons, when the college football team is dealing with this part of the training, they often use the pre-season system team not the whole year system team. Football is a collective movement, in the game, the 11 people must keep thinking unity, consistent action, attack or defense together, the overall sense of war must be strong. 
In the University coach System, Most of the Football Teachers are Coming from Colleges. This situation determines that the college football team coaches not only focus on college football team training work, but also take part of the energy in football regular teaching, football research work even the student political work. From another point of view, the college football team coach most are non-professional athlete origin, although there is a certain of theoretical knowledge, but from the professional skills and teaching experience point of view, they are still deficiencies, which makes college football training encounter bottlenecks, but also make the development of college football training system limited.

During the Long Time Development Process, due to the lack of scientific reform and improve the management system, the lack of a clear direction of development, the Chinese football making breeding of a series of complex social problems and ugly social phenomenon in the process of reform. Leading to the Chinese football has lost both the original institutional advantages, as well as the tenacious struggle, hard work and other fine traditions of sports industry, and did not play the role of professional sports promotion function. On the contrary, it makes more and more people fear to talk about Chinese football, choose to stay away from the Chinese football indefinitely.

\section{Analysis on the Advantages of Football Talents in Colleges of our Country}

The Advantage of College Football Atmosphere. The low level of China's football has a close relationship with lower the football atmosphere. Doing a good job for football culture, and the people to participate in football game will naturally become more. The cornerstone of the football population will naturally grow, which will create far-reaching significance for the development of football naturally. The high school football atmosphere here does not simply mean that the presence of high-level football teams in football and the participation of football professionals in the football, it also includes the atmosphere that non-sports professional school students participate in the of football activities, this kind of atmosphere even has a certain relationship with surrounding campus football environment.

The advantage of national college football population. The population here refers to the student source in the full-yard system undergraduate, full-time graduate students, doctoral students, foreign students, correspondence students and other students. The level of a country's football mostly depend on the fundamental factor that how much the country's football population. The most fundamental driving force of the football population depends on the number of football population in right age. Colleges as intensive places of young people crowding, is the gathering place of football culture. From this point of the right age of the population, the university is undoubtedly having the unique advantage.

The Spirit Advantage of Our Country College Football. College campus football as a special group, in the process of participation, most of us are holding this simple love of football to participate in. It is not important to be able to obtain material or other incentives. Just such a mentality, it restores the most pure football value, but also makes the college campus football grow and develop in a good environment. There is no doubt that higher spiritual realm is also become an advantage for college football talent.

\section{The Countermeasures for the Present Situation of Football Future Development in China}

Integrate College Resources, and Improve the Amateur Training System. In the process of football development in colleges, we must pay attention to the optimal allocation of football teachers and coaches. By arranging the best football training staff reasonably to take part in the daily training and curriculum learning the two links, taking the high level football team construction as the flag to guide and attract more students to participate in college football. And then regard the popularity of college football as a guarantee, to select more outstanding student players into the high level sports team. And finally through the mutual coordination and mutual promotion, so as to achieve the resources optimization of the college football teachers and coaches, to improve the amateur training system. 
Football Special Students Enrollment System Construction. Improve the primary school, junior school, senior high school, college football special students enrollment policy, develop football reserve talent identification standards and school management system, to further expand the number of colleges to recruit high-level football players, to smoothen channel for output the football talent players, gradually smoothen football team construction and operation mechanism of taking the colleges as the "leading" to build football team from primary, secondary schools to colleges. To allow the designated schools to recruit football specialty students. But for the current domestic environment, very few colleges are willing to treat recruiting football specialty students as enrollment projects, and more places were replaced by ping-pang ball, badminton, tennis and other small ball projects. Therefore, the national sports functional departments and education departments must set up a well-established enrollment system as a top priority thing to do, so that the level of football of colleges can continue to be improved.

Unite College Functions, Establish College Football Training System,As the college football players have both a player and a student dual identity, reading and training contradictions will naturally be reflected in the training. Therefore, it is recommended that college football decision-making joint functional departments responsible for the development establish college football training system. First of all, the system should clearly point out how to coordinate the class, examination questions for the students in the training and competition. Second, a clear reward and punishment system should be built for the team members who achieve the results and problems during the training and the game.

\section{Summary}

China's football development shows a serious polarization phenomenon in some colleges, therein, the implement level of part of the eastern colleges is higher than the central and western regions. But generally affected by the training system, funding, venues, policy protection and the domestic football environment, the overall level of development is not high and not ideal. Colleges is a resourceful place for talent students, the development of college football has a unique talent advantage, which are reflected in the humanities, education, and technology and so on. The development of football in colleges and universities can take these talents as the carrier, and constantly improve and innovate and realize the sustainable development.

\section{References}

[1] OddsShark. Ohio State, Alabama early favorites to make College Football Playoff[J]. 2015.

[2] Liu K. Rethink of the College Football Promotion in China [J]. Journal of Chengdu Sport University, 2014.

[3] Deitsch R. College football TV analysts weigh in on upcoming season and more [J]. Sports Illustrated Com, 2015.

[4] Ellis Z, Schnell L. College Football Podcast: Preview, picks for Alabama-Michigan State[J]. Sports Illustrated Com, 2015.

[5] Becht C. Florida climbs into top four in college football Power Rankings after Week 9[J]. Sports Illustrated Com, 2015.

[6] Mustard E. College Football Superfans: Best Halloween costumes in the stands [J]. Sports Illustrated Com, 2015.

[7] Ellis Z, Schnell L. College Football Podcast: Can Bama, Clemson return to the title game?[J]. Sports Illustrated Com, 2016.

[8] OddsShark. College football Week 7 odds: Betting odds for most notable matchups [J]. Sports Illustrated Com, 2015.

[9] OddsShark. College football odds: Hot Stanford favored by double digits over Oregon [J]. Sports Illustrated Com, 2015.

[10] Shi G M. Situation analysis and innovation road of College football teaching [J]. Heilongjiang Science, 2016. 
[11] Staples A. Answering College Football Playoff rankings questions; \#DearAndy [J]. Sports Illustrated Com, 2015.

[12] Ellis Z, Schnell L. College Football Podcast: Preview, picks for Clemson-Oklahoma[J]. Sports Illustrated Com, 2015. 